\title{
Effects of Nitroglycerin, Adenosine, Noradrenaline, and Isoproterenol on the Myocardial Oxygen Tension
}

\author{
Hiroto Matsuda, M.D.
}

\section{SUMmaRY}

The effects of adenosine, nitroglycerin, noradrenaline, and isoproterenol on the myocardial oxygen tension were studied. The oxygen tension was measured by a polarographic method.

Adenosine and nitroglycerin (intravenous and intracoronary injections) did not produce a beneficial effect on the normal myocardium. Intravenous administration of noradrenaline produced an increase in subendocardial oxygen tension, while intravenous administration of isoproterenol decreased subendocardial oxygen tension. However, intracoronary administration of catecholamines increased myocardial oxygen tension.

These results suggest that in the absence of systemic hemodynamic changes, catecholamines produce a beneficial effect on the normal myocardium, but administration of adenosine and nitroglycerin (intravenous and intracoronary injections) have no beneficial effect.

The effects of several physiological parameters on the myocardial oxygen tension were studied. Pacing with a higher rate resulted in a decrease in subendocardial oxygen tension. When the perfusion pressure was lowered, subendocardial oxygen tension was decreased. When the perfusion pressure was raised, subendocardial oxygen tension was increased.

\section{Additional Indexing Words :}

Antianginal agent Catecholamine $\mathrm{PO}_{2} \quad$ Physiological parameters Normal myocardium

T $T$ is well established that nitroglycerin is an effective antianginal agent both in the angina of effort and the angina at rest. Anginal pain is generally thought to be due to myocardial hypoxia. Therefore, it is of interest whether nitroglycerin produces an improvement of oxygenation of myocardium. Several years ago, Winbury ${ }^{\mathbf{1}}$ and Weiss ${ }^{2}$ measured subepicardial and subendocardial tissue oxygen tension $\left(\mathrm{Po}_{2}\right)$ and reported that intravenous administration of nitroglycerin resulted in a biphasic change in subendocardial $\mathrm{Po}_{2}$, i.e. initial fall followed by a rise over control level. They

From the Department of Pharmacology, Niigata University School of Medicine, Niigata 951, Japan.

Received for publication February 5, 1979.

Manuscript revised March 13, 1979. 
further observed that intracoronary injection of nitroglycerin produced only an elevation of subendocardial $\mathrm{Po}_{2}$. However, as the platinum bare-tip electrodes they used for $\mathrm{Po}_{2}$ determinations are fraught with errors, especially those resulting from the changes in the coronary blood flow, the author attempted to reexamine the effects of nitroglycerin on the myocardial $\mathrm{Po}_{2}$ using the hydron-coated gold electrodes (IBC 660-001). In addition, the effects of several physiological factors and endogenous substances on the myocardial $\mathrm{Po}_{2}$ were also studied.

\section{Materials and Methods}

\section{Intravenous administration of several agents:}

Eighteen mongrel dogs of both sexes, weighing from 8 to $16 \mathrm{Kg}$ were anesthetized with subcutaneous morphine $(1.5 \mathrm{mg} / \mathrm{Kg}$ ) followed by urethane (450 $\mathrm{mg} / \mathrm{Kg}$ ) $+\alpha$-chloralose $(45 \mathrm{mg} / \mathrm{Kg}$ ) (i.v.) and ventilated artificially with room air via an endotracheal tube with a positive pressure respirator $(20 / \mathrm{min})$. Tidal volume was set at $20 \mathrm{ml} / \mathrm{Kg}$. Thoracotomy was performed through the 5 th and 6 th intercostal spaces. After cutting the pericardium and cradling the heart, the middle third of the left anterior descending coronary artery was isolated from the surrounding tissues. An electromagnetic flowmeter probe (Statham Model 2201) was placed around the artery. Zero-flow references were obtained by occuluding the vessel distal to the probe. The calibration was done with isolated arteries of suitable length and diameter, which were cannulated at both ends and perfused with blood at approximately $37^{\circ} \mathrm{C}$ from a gravity fed reservoir into a graduated cylinder. A catheter was introduced into the right femoral artery to measure mean aortic pressure with a pressure transducer (Nihonkohden LPU 0.5) coupled with a carrier-amplifier (Nihonkohden RP-5). The heart rate was counted with a cardiotachometer (Nihonkohden RT-5), which was triggered by the R wave of the standard limb lead II ECG. Tissue oxygen tension of the subendocardial region was measured with a $\mathrm{Po}_{2}$ electrode with a response time of less than $30 \mathrm{sec}$ (International Biophysics Corporation 660-001). The diameter of the gold electrode was $20 \mu \mathrm{m}$. However, because it was coated with hydron the external diameter was $380 \mu \mathrm{m} .{ }^{3)} \quad$ The IBC electrode has been free from pressure or flow artifact and has shown no indication of electrode poisoning. With an adequate equilibration time (20-30 min), the coated electrodes we used showed a negligible drift and excellent reproducibility. The electrode was pierced into an area nourished by the left anterior descending coronary artery. The depth of the electrode and the thickness of the myocardium were measured when the experiment was finished. The electrodes were calibrated in saline $\left(37^{\circ} \mathrm{C}\right)$, equilibrated with various concentrations of oxygen. Negative $0.72 \mathrm{~V}$ was applied between the $\mathrm{P}_{\mathrm{O}_{2}}$ electrode and the reference electrode (silver/silver chloride). Current flowing between these 2 electrodes was measured by the D.C. amplifier (IBC 630-001) via a photocoupler (Contex-Inc) and recorded on an ink-writing oscillograph (Watanabe WTR 281).

2. Intracoronary administration of agents:

Seventeen mongrel dogs of both sexes weighing from 9 to $18 \mathrm{Kg}$ were used. Anesthesia, respiration, and surgical procedures were the same as in the preceding 
section. Heparin (500 unit/Kg) was injected intravenously to heparinize the whole body. The middle third of the left anterior descending coronary artery was isolated from the surrounding tissue, and cannulated. It was perfused with the blood from the right carotid artery. The coronary blood flow was recorded with Statham electromagnetic flowmeter (Model SP 2201) equipped with a cannulating-type probe. With a constant perfusion pressure device (Datagraph SCS 21), the perfusion pressure was maintained at $100 \mathrm{mmHg}$ throughout the entire course of the experiment and was recorded with a pressure transducer (Nihonkohden LPU 0.5). Other procedures were the same as in the preceding section. Drugs were dissolved in $0.9 \%$ saline and injected into the rubber-tubing leading to the cannula inserted into the anterior descending branch of the left coronary artery in a volume of 10-30 $\mu$ over period of $2-4 \mathrm{sec}$ by microsyringes.

Drugs used were: nitroglycerin provided by Nippon Kayaku as a $10 \mathrm{mg} / \mathrm{ml}$ solution in ethanol, adenosine (Sigma Chemical), dl-noradrenaline hydrochloride (Sankyo), and 1-isoproterenol hydrochloride (Nikken Kagaku).

\section{Results}

In 35 control measurements, subendocardial tissue $\mathrm{Po}_{2}$ was $25.6 \mathrm{mmHg}$ $\pm 1.2(\mathrm{n}=35)$. When the dog was respirated with $95 \% \mathrm{O}_{2}+5 \% \mathrm{CO}_{2}$ instead of room air for $10 \mathrm{~min}$, subendocardial $\mathrm{Po}_{2}$ rose by $6 \mathrm{mmHg}$ (Fig. 1). Occlusion of LAD for $2 \mathrm{~min}$ resulted in a reduction of subendocardial $\mathrm{Po}_{2}$ by 3 $\mathrm{mmHg}$. On reperfusion, reactive hyperemic responses were observed. However, the subendocardial $\mathrm{Po}_{2}$ did not show any overshoot above the control value; it returned to the control value in $10 \mathrm{~min}$ (Fig. 2). In some cases, occlusion of LAD brought about an increase in subendocardial $\mathrm{Po}_{2}$, suggesting that the blood supply to the area was from the circumflex branch.

1. Intravenous administration of several agents:

1) Effect of adenosine

Adenosine is thought to be a mediator of the ischemic dilatation of the

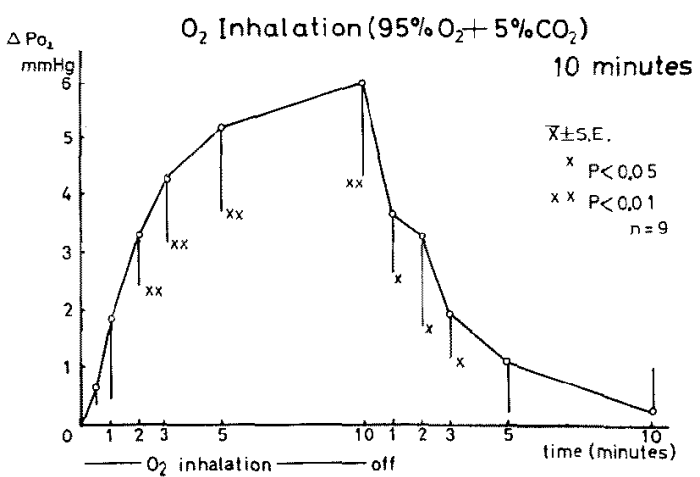

Fig. 1. Effect of $\mathrm{O}_{2}$ inhalation $\left(95 \% \mathrm{O}_{2}+5 \% \quad \mathrm{CO}_{2}\right) . \Delta \mathrm{Po}_{2}=$ Changes in myocardial oxygen tension. Vertical bar represents S.E. of the mean. ${ }^{*}=\mathrm{p}<0.05 ;{ }^{* *}=\mathrm{p}<0.01$ compared with control by Student's t-test. 


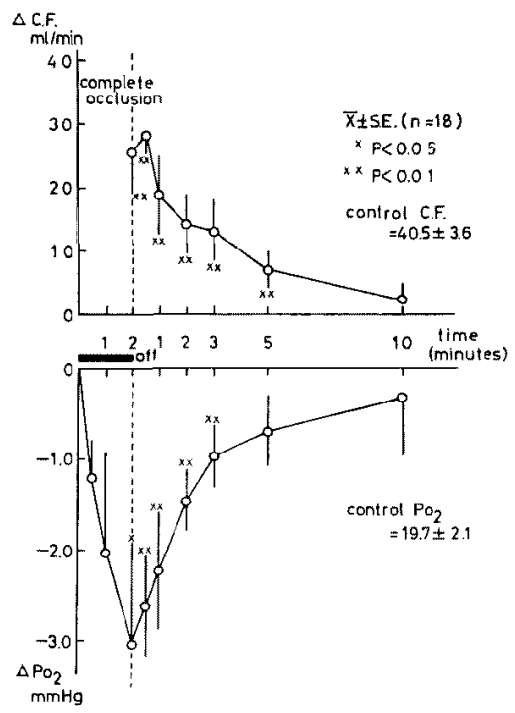

Fig. 2. Effects of coronary occlusion (left anterior descending artery). $\Delta \mathrm{C} . \mathrm{F} .=$ Changes in coronary flow; $\Delta \mathrm{Po}_{2}=$ Changes in myocardial oxygen tension. Vertical bar represents S.E. of the mean. ${ }^{*}=\mathrm{p}<0.05 ;{ }^{* *}=$ $\mathrm{p}<0.01$ compared with control by Student's t-test.

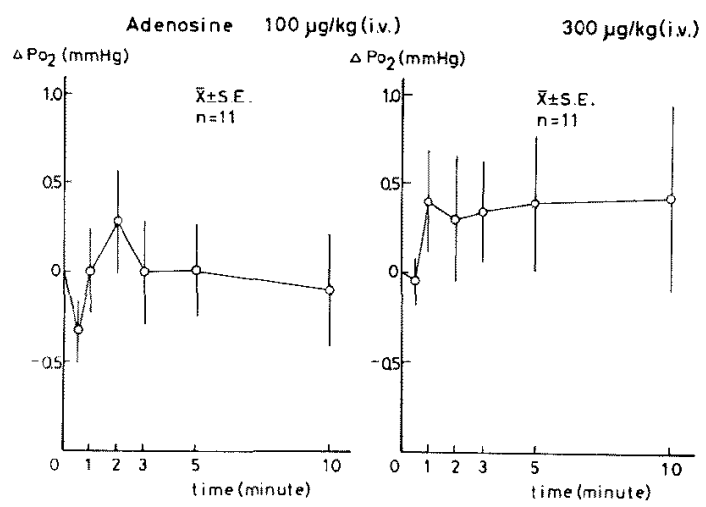

Fig. 3. Effect of $100-300 \mu \mathrm{g} / \mathrm{Kg}$ (i.v.) of adenosine on the myocardial oxygen tension. Vertical bars represent S.E. of the mean.

coronary blood vessel. When administered intravenously in doses of $100-$ $300 \mu \mathrm{g} / \mathrm{Kg}$, it produced a fall of the aortic pressure. Heart rate was either increased or decreased depending on the intensity of the baroreceptor reflex. Although coronary blood flow was increased dose-dependently, there was no significant changes in subendocardial $\mathrm{Po}_{2}$ (Fig. 3).

2) Effect of nitroglycerin

Nitroglycerin in doses of 10,30 , and $100 \mu \mathrm{g} / \mathrm{Kg}$ administered intravenously decreased aortic pressure and increased heart rate. There was 
transient increase in coronary flow lasting for only a few minutes. Subendocardial $\mathrm{Po}_{2}$ was decreased dose-dependently (Fig. 4). There was a good correlation between the decrease in $\mathrm{Po}_{2}\left(\Delta \mathrm{Po}_{2}\right)$ and the fall in the blood pressure $(\triangle \mathrm{BP})$, as illustrated in Fig. 5, while there was no significant correlation between the changes in heart rate $(\Delta \mathrm{HR})$ and $\Delta \mathrm{Po}_{2}$ (Fig. 5). Therefore, it may be inferred that the decrease in subendocardial $\mathrm{Po}_{2}$ is a consequence of a decrease in systemic blood pressure.

3) Effect of noradrenaline

Noradrenaline in doses of 1 and $3 \mu \mathrm{g} / \mathrm{Kg}$ administered intravenously

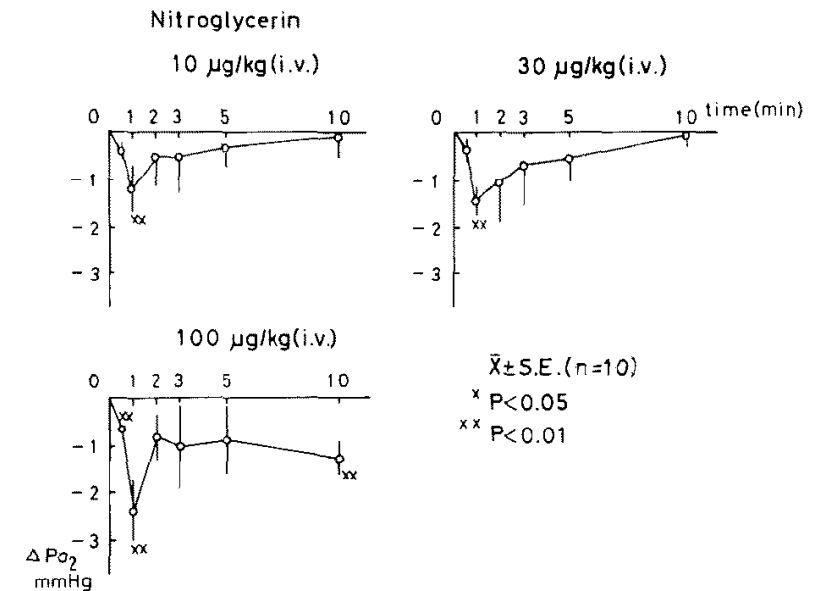

Fig. 4. Effect of $10-100 \mu g / K g$ (i.v.) of nitroglycerin on the myocardial oxygen tension. Vertical bars represent S.E. of the mean. *=significant at $\mathrm{p}<0.05 ; * *=$ significant at $\mathrm{p}<0.01$.

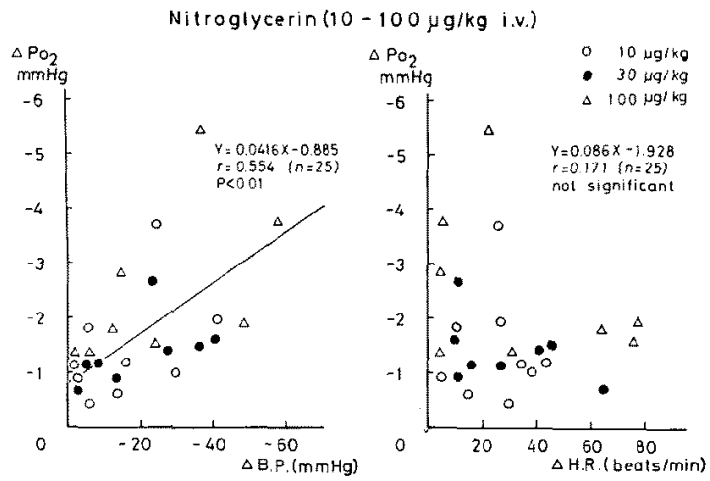

Fig. 5. Left: Relationship between the fall in blood pressure and the decrease in myocardial oxygen tension after administration of nitroglycerin (i.v.). Right: Relationship between the increase in heart rate and the decrease in myocardial oxygen tension after administration of nitroglycerin (i.v.). 


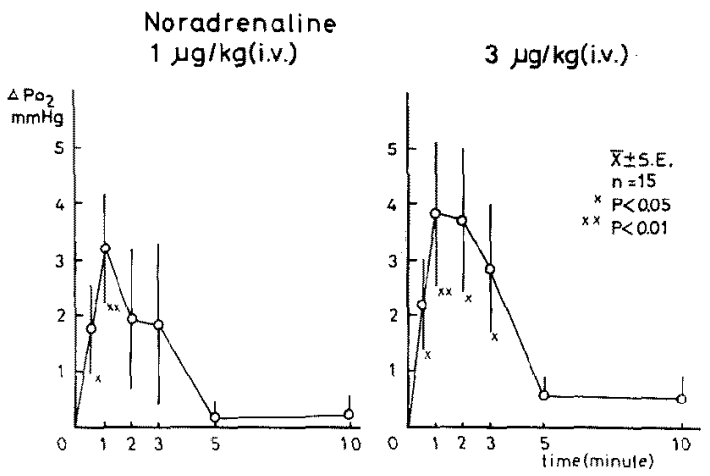

Fig. 6. Effect of $1-3 \mu \mathrm{g} / \mathrm{Kg}$ (i.v.) of noradrenaline on the myocardial oxygen tension. Abbreviations are the same as in Fig. 4.

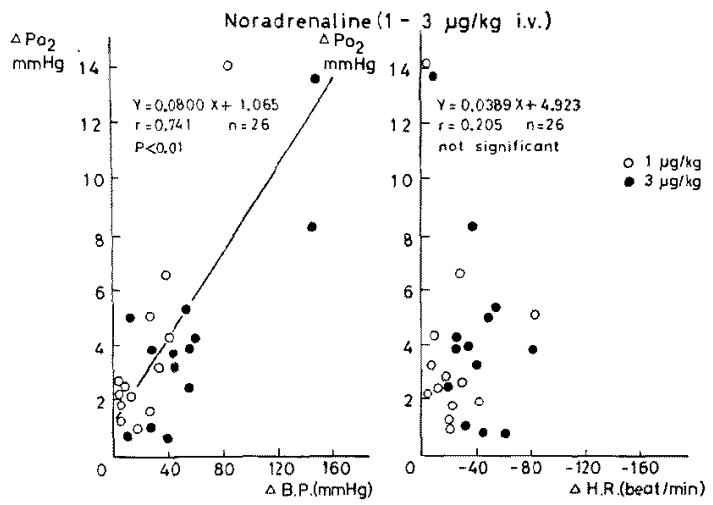

Fig. 7. Left: Relationship between the increase in blood pressure and the increase in myocardial oxygen tension after administration of noradrenaline (i.v.). Right: Relationship between the decrease in heart rate and the increase in myocardial oxygen tension after administration of noradrenaline (i.v.).

produced a rise of aortic pressure which was associated with a reflex decrease in the heart rate. Coronary flow was increased. Subendocardial $\mathrm{Po}_{2}$ was increased dose-dependently (Fig. 6). There was a good correlation between $\Delta \mathrm{PO}_{2}$ and $\triangle \mathrm{BP}$ as shown in Fig. 7.

4) Effect of isoproterenol

Isoproterenol in doses of 0.1 and $0.3 \mu \mathrm{g} / \mathrm{Kg}$ given intravenously produced a fall of aortic pressure and an increase in the heart rate. Although coronary flow was increased dose-dependently, subendocardial $\mathrm{Po}_{2}$ was decreased dose-dependently (Fig. 8). There was a good correlation between $\Delta \mathrm{HR}$ and $\Delta \mathrm{PO}_{2}$ and between $\Delta \mathrm{B}$.P. and $\Delta \mathrm{Po}_{2}$ (Fig. 9), indicating that the increase in the heart rate and fall of the blood pressure were responsible for the observed decrease in myocardial $\mathrm{Po}_{2}$. 


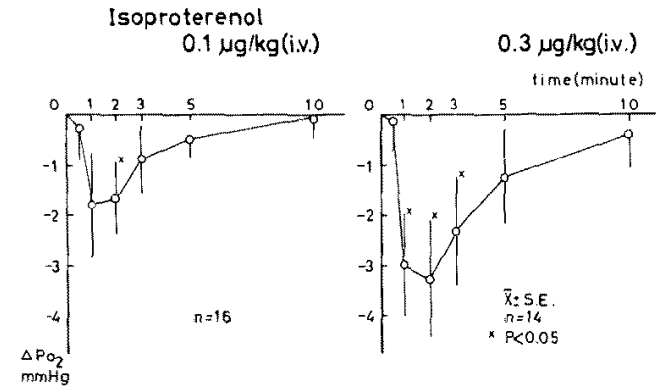

Fig. 8. Effect of $0.1-0.3 \mu \mathrm{g} / \mathrm{Kg}$ (i.v.) of isoproterenol on the myocardial oxygen tension. Abbreviations are the same as in Fig. 4.

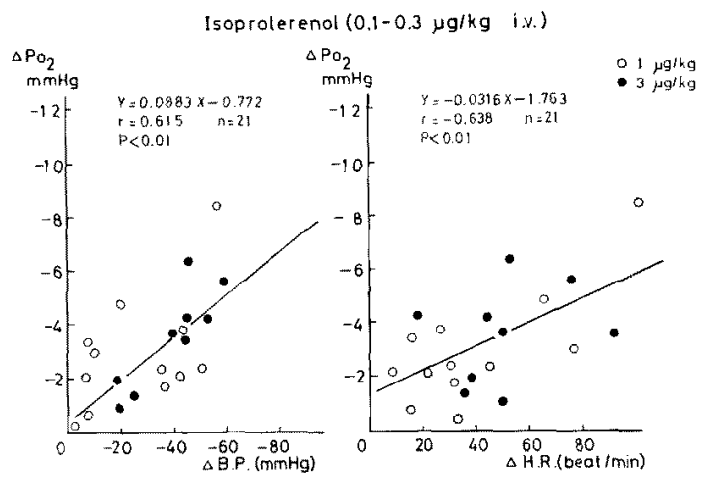

Fig. 9. Left: Relationship between the fall in blood pressure and the decrease in myocardial oxygen tension after administration of isoproterenol (i.v.). Right: Relationship between the increase in heart rate and the decrease in myocardial oxygen tension after administration of isoproterenol (i.v.).

2. Intracoronary (i.a.) administration of several agents:

When drugs were injected i.a., there was no change in the blood pressure or in the heart rate. Under these conditions, adenosine 0.1-30 $\mu \mathrm{g}$ produced a dose-related decrease in $\mathrm{Po}_{2}$ with a dose-related increase in the coronary flow (Fig. 10). There was no definite change in the heart rate. Nitroglycerin 1-30 $\mu$ g produced a dose-related increase in coronary flow, while the subendocardial $\mathrm{PO}_{2}$ was decreased dosc-dependently (Fig. 10). Noradrenaline $0.01-0.1 \mu \mathrm{g}$ produced an increase in the coronary flow and an increase in the subendocardial $\mathrm{Po}_{2}$. These changes were dose-related as shown in Fig. 11. A larger doses of noradrenaline $(0.3-1 \mu \mathrm{g})$ also increased coronary flow. However subendocardial $\mathrm{Po}_{2}$ was decreased after a transient increase. Isoproterenol $(0.001-0.03 \mu \mathrm{g})$ produced an increase in the coronary flow, and in the subendocardial $\mathrm{PO}_{2}$ (Fig. 11). However, larger doses of this substance produced a fall of $\mathrm{PO}_{2}$ after initial rise, although it produced an in- 


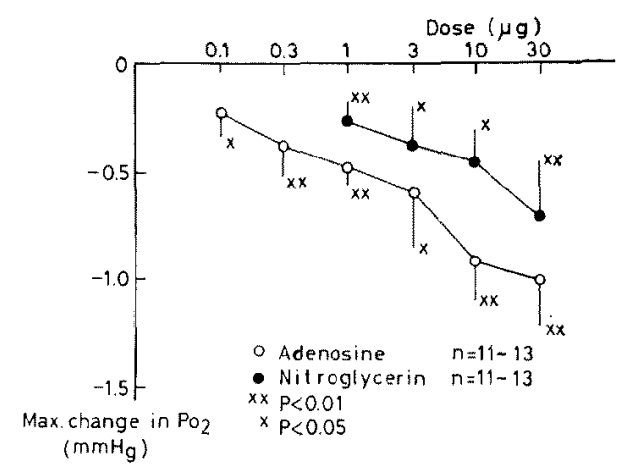

Fig. 10. Effects of adenosine (0.1-30 $\mu \mathrm{g}$, intracoronary injection) and nitroglycerin (1-30 $\mu \mathrm{g}$, intracoronary injection) on the myocardial oxygen tension. Abbreviations are the same as in Fig. 4.

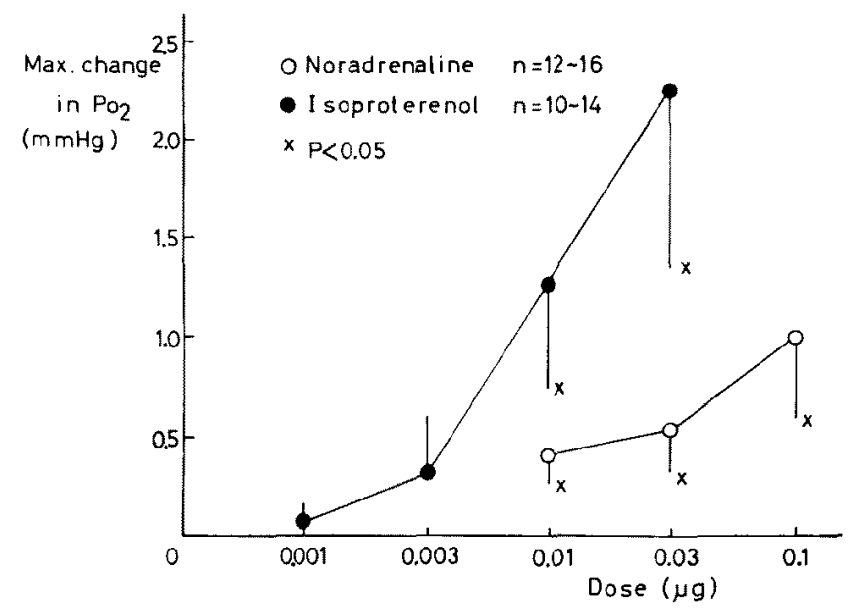

Fig. 11. Effects of isoproterenol (0.001-0.03 $\mu \mathrm{g}$, intracoronary injection) and noradrenaline $(0.01-0.1 / \mathrm{g}$, intracoronary injection) on the myocardial oxygen tension. Abbreviations are the same as in Fig. 4.

crease in the coronary flow.

3. Effects of changes in physiological parameters:

1) Effects of pacing

It is well known that there is a close correlation between oxygen consumption and heart rate. In order to delineate the effects of changes in the heart rate on the myocardial $\mathrm{Po}_{2}$, bipolar electrodes were placed on the left atrium and the heart was paced at rates of 180, 210, and 240. Pacing with a higher rate resulted in a decrease in subendocardial $\mathrm{Po}_{2}$, which was associated with an increase in the coronary blood flow (Fig. 12).

2) Effects of the perfusion pressure

The effect of changing the perfusion pressure on the myocardial $\mathrm{Po}_{2}$ 

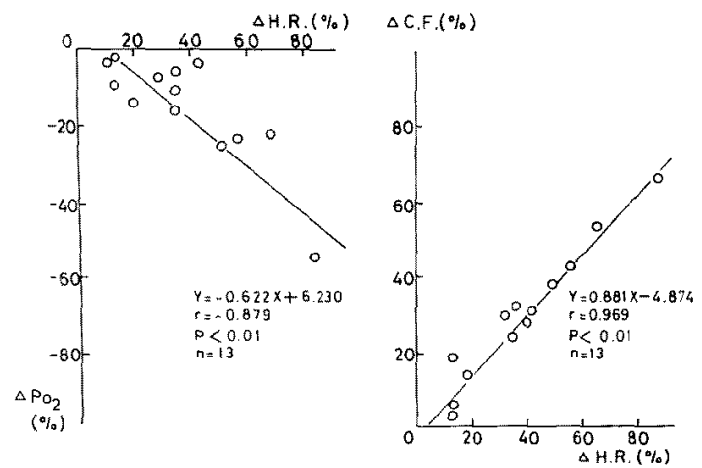

Fig. 12. Effects of left atrial pacing on the myocardial oxygen tension and the coronary flow. Left: Relationship between the increase in heart rate and the decrease in myocardial oxygen tension. Right: Relationship between the increase in heart rate and the increase in coronary flow.

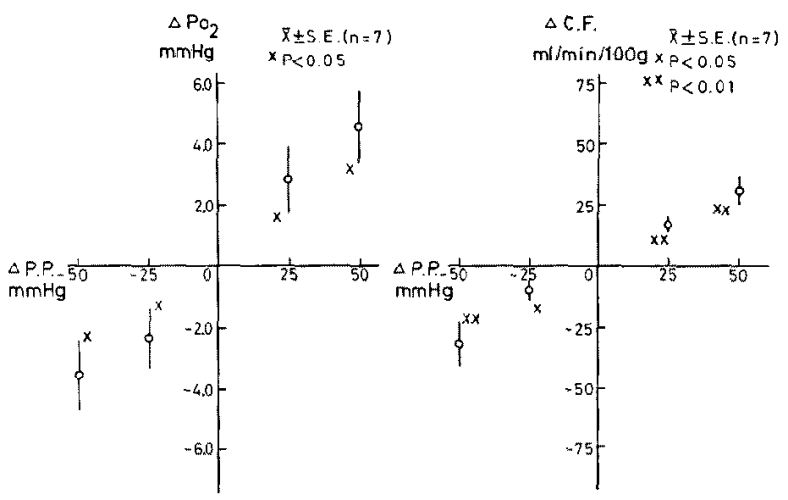

Fig. 13. Left: Effect of changing the perfusion pressure on the myocardial oxygen tension. Vertical bars represent S.E. of the mean. ${ }^{*}=\mathrm{p}<$ $0.05 ; \Delta \mathrm{P} . \mathrm{P} .=$ Changes in perfusion pressure; $\Delta \mathrm{Po}_{2}=$ Changes in myocardial oxygen tension. Right: Effect of changing the perfusion pressure on the coronary flow. ${ }^{*}=\mathrm{p}<0.05 ; * *=\mathrm{p}<0.01, \Delta \mathrm{P} . \mathrm{P} .=$ Changes in perfusion pressure; $\Delta \mathrm{C} . \mathrm{F} .=$ Changes in coronary flow.

was studied in preparations, in which the anterior descending branch was perfused under constant perfusion pressure. When the perfusion pressure was lowered to 75 and $50 \mathrm{mmHg}$, subendocardial $\mathrm{Po}_{2}$ was decreased (Fig. 13). At the same time, coronary flow was decreased. When the perfusion pressure was raised to 125 and $150 \mathrm{mmHg}$, subendocardial $\mathrm{Po}_{2}$ was increased (Fig. 13). However, owing to the presence of autoregulation, changes in the coronary blood flow were minimal as shown in Fig. 13. 


\section{Discussion}

Myocardial $\mathrm{Po}_{2}$ we measured reflects a local balance between $\mathrm{O}_{2}$ supply and $\mathrm{O}_{2}$ demand. According to Winbury, ${ }^{4}$ the oxygen supply to tissue is dependent on

1. proper arterial saturation at the lung

2. adequate coronary inflow

3. proper distribution between epicardium and endocardium

4. capillary circulation

5. transport from blood to tissue

6. transport to mitochondria, and the oxygen demand is dependent on

1. cardiac fiber length

2. diastolic wall tension

3. systolic pressure and wall tension

4. contractile state

5. heart rate and ejection time

Thus, there are many factors which regulate myocardial $\mathrm{Po}_{2}$.

Although nitroglycerin is an effective antianginal agent, the mechanism of its beneficial effect is still unknown. Fam et $a^{5)}$ reported that intravenous nitroglycerin produced a prolonged increase in the blood flow in ischemic area with no change in the normal area, while $\mathrm{Kadat}^{6)}$ reported a variable and biphasic pattern with nitroglycerin. Winbury ${ }^{1)}$ reported that intravenous administration of nitroglycerin produced an initial decline of endocardial and epicardial $\mathrm{PO}_{2}$. However, as coronary flow and aortic pressure returned to normal level, endocardial $\mathrm{Po}_{2}$ increased above control level while the epicardial $\mathrm{PO}_{2}$ returned to the normal level. These findings indicate that the fall of blood pressure and consequent decrease in blood supply induced by intravenous nitroglycerin was the cause of the decline of endocardial $\mathrm{P}_{2}$. Although Winbury et al reported that both intravenous and intracoronary administration of nitroglycerin increased nutritional blood flow, Bernstein ${ }^{7}$ reported that intravenous administration of nitroglycerin decreased nutritional flow, while intracoronary administration increased.

In the present experiment, even the intracoronary administration of nitroglycerin resulted in a decrease in subendocardial $\mathrm{Po}_{2}$. This is in contrast to the findings of Winbury et $\mathrm{al}^{11}$ and Weiss et $\mathrm{al}^{2}$ ) who showed that the same procedures produced a selective increase in endocardial $\mathrm{Po}_{2}$. The bare tip electrodes used by Winbury and Weiss for $\mathrm{Po}_{2}$ determinations are fraught with a mechanical artifact, while the coated electrodes we used are free from the error, ${ }^{8}$ ' although the response is slower. It is true that the diameter of 
our electrode is larger ( $380 \mu \mathrm{m}$ including the hydron coating) compared with the bare-tip electrodes of Winbury and Weiss $(177 \mu \mathrm{m})$, but the $\mathrm{Po}_{2}$ values obtained in the present study were quite stable and low, indicating that there was no severe tissue damage whatsoever. Although this seems to be contradictory to the general belief that the tissue damage is the greater, the greater the diameter of the electrode is, ${ }^{9}$ it may be due to the fact that the hydron became softer once in tissue, causing no serious irritation of the surrounding tissue. A decrease in tissue $\mathrm{Po}_{2}$ produced by adenosine may have resulted from a steal phenomenon as reported by Cohen, ${ }^{10)}$ who showed that administration of adenosine increased the coronary blood flow, but reduced the endocardial blood flow in the ischemic area. There is a possibility that nitroglycerin also produced a steal phenomenon in the subendocardial area. The blood flow in the subendocardial region is more critically dependent upon the perfusion pressure, i.e. the difference between the arterial blood pressure and the ventricular end-diastolic pressure, than the subepicardial blood flow and unlike intravenous administration, intraarterial administration of nitroglycerin could not produce a decrease in the latter due to the lack of systemic hemodynamic effects. In fact, it is reported by Forman ${ }^{11}$ that intracoronary administration of nitroglycerin decreased subendocardial blood flow in the ischemic area.

It is well known that injection of noradrenaline and isoproterenol provoke anginal attacks. However in the present experiment intracoronary as well as intravenous administration of noradrenaline increased myocardial $\mathrm{Po}_{2}$, in agreement with the results obtained by Sayen et $\mathrm{al}^{12}$ that intravenous and intracoronary injection of noradrenaline increased myocardial $\mathrm{Po}_{2}$. Beneficial effects of intravenous noradrenaline are not difficult to explain, for subendocardial $\mathrm{Po}_{2}$ is dependent on the arterial pressure, as shown in Fig. 7, and intravenous noradrenaline produces a marked rise of blood pressure. Why intracoronary noradrenaline produced a beneficial effect is hard to explain. Presumably the augmentation of the perfusion pressure resulted from the fall of the ventricular end-diastolic pressure as reported by Shoji et al $(1978)^{13)}$ brought about a better irrigation of the subendocardial myocardium. The fact that the intracoronary administration of isoproterenol resulted in a similar improvement may also be explained on the same basis.

Winsor et $\mathrm{al}^{\mathbf{1 4})}$ reported that intravenous injection of isoproterenol reduced endocardial $\mathrm{Po}_{2}$. Maroko et $\mathrm{al}^{15)}$ reported that intravenous isoproterenol produced precordal ST segment elevation. These reports are consistent with our results. Since intracoronary injection of isoproterenol increased subendocardial $\mathrm{Po}_{2}$ in the present experiments, decrease in $\mathrm{Po}_{2}$ produced by i.v. isoproterenol may be attributed to a fall of blood pressure 
combined with positive inotropic and chronotropic effects produced by this substance, as postulated by $\mathrm{Rona}^{16)}$ and Handforth ${ }^{17)}$ resulting in the cardiac necrosis produced by this substance (Uchida, ${ }^{18)}$ Winsor et al ${ }^{14)}$ ). The metabolic effect of this substance cannot be ruled out (Rosenblum et al ${ }^{19}$ ). In conclusion, it may be said that in the absence of systemic hemodynamic changes, and of changes in the gross cardiohemodynamics, especially the increase in the heart rate, injection of noradrenaline and isoproterenol can produce a beneficial effect on the oxygenation of the normal endocardium.

\section{Acknowledgements}

The author thanks Prof. S. Imai, the Department of Pharmacology, Niigata University School of Medicine, for his constructive criticism on the manuscript, emeritus Prof. M. Matsuoka, Prof. A. Shibata, and associate Prof. K. Tamura, the Department of Internal Medicine, Niigata University School of Medicine, for providing the opportunity for this experiment.

Thanks are also due to Dr. T. Tsukada, Mr. Y. Nakagawa, the Department of Pharmacology, Niigata University School of Medicine, for the earnest cooperation, Mr. H. Sakurai, for technical assistance, and Miss K. Nomura for typing the manuscript.

\section{REFERENGES}

1. Winbury MM, Howe BB, Weiss HR: Effect of nitroglycerin and dipyridamole on epicardial and endocardial oxygen tension. Further evidence for redistribution of myocardial blood flow. J Pharmacol 176: 184, 1971

2. Weiss HR, Winbury MM: Intracoronary nitroglycerin, pentaerythritol trinitrate and dipyridamole on intramyocardial oxygen tension. Microvasc Res 4: 273, 1972

3. Sugioka $\mathrm{K}$ : Theoretical and clinical consideration on the use of a new in vivo oxygen electrode. in Oxygen Measurements in Biology and Medicine, ed by Payne JP, Hille DW, Butterworths, London and Boston, p111-120, 1975

4. Winbury MM: Experimental coronary disease-models and methods of drug evaluation. in Handbook of Experimental Pharmacology, Vol XVI, Experimental Producticn of Disease, Part 3, Heart and Circualtion, ed by J Schnier, U Eichler, Springer-Verlag, New York, Berlin, Heiderberg, p1-69, 1975

5. Fam WM, Nakhjavan FK, Sekely P, McGregor M: The effects of oxygen breathing, nitroglycerin and dipyridamole in healthy and ischemic areas of the myocardium. in Cardiovascular and Respiratory Fffects of Hypoxia, ed by JD Hatcher, DB Jennings, S Karger, New York, p375-390, 1966

6. Kadatz R: Sauerstoffdruck und Durchblutung in gesunden und koronarinsuffizienten Myokard des Hundes und ihre Beeinflussung durch Koronareweiternde Pharmaka. Arch Kreislaufforsch 58: 263, 1969

7. Bernstein L, Friesinger GC, Lichtlen PR, Ross RS: The effect of nitroglycerin on the systemic and coronary circulation in man and dogs. Myocardial blood flow measured with xenon ${ }^{13 a}$. Girculation 33: 107,1966

8. Fatt I: Influence of moving liquid on polarographic oxygen sensor current. in Polarographic Oxygen Sensor. Its Theory of Operation and Its Application in Biology, Medicine, and 
Technology, CRC Press, Inc, Cleveland, p19-24, 1976

9. Moss AJ: Intramyocardial oxygen tension. Cardiovasc Res 3: 314,1968

10. Cohen MV, Sonnenblick EH, Kirk ES: Coronary steal. Its role in detrimental effect of isoproterenol after acute coronary occlusion in dogs. Am J Cardiol 38: 880, 1976

11. Forman R, Kirk ES, DowneyJM, Sonnenblick EH: Nitroglycerin and heterogeneity of myocardial blood flow. Reduced subendocardial blood flow and ventricular contractile force. J Clin Invest 52: 905, 1973

12. Sayen JJ, Katcher WF, Sheldon WF, Gilbert CH: The effect of levarterenol on polarographic myocardial oxygen, the epicardial electrocardiogram and contraction in nonischemic dog hearts and experimental acute regional ischemia. Circulat Res 8: 109, 1960

13. Shoji $T$, Iimura $O$, Wakabayashi C: Effects of a physiological dose of noradrenaline on hemodynamics and myocardial metabolism in dogs with graded coronary constraction. J Jap College Angiology 18: 375, 1978 (in Japanese)

14. Winsor $\mathrm{T}$, Mills B, Winbury MM, Howe BB, Berger $\mathrm{HJ}$ : Intramyocardial diversion of coronary blood flow. Effects of isoproterenol-induced subendocardial ischemia. Microvasc Res 9: 261,1975

15. Maroko PM, Kjekshus JK, Sobel BE, Watanabe T, Covell JW, Ross J Jr, Braunwald E: Factors influencing infarct size following experimental coronary artery occlusions. Circulation 43: 67, 1971

16. Rona G, Kahn DS, Chappel CI: Studies on infarct-like myocardial necrosis produced by isoproterenol. A review. Rev Cand Biol 22: 241, 1963

17. Handforth CP: Myocardial infarction and necrotizing arteritis in hamsters, produced by isoproterenol. Med Serv J Can 18: 506, 1962

18. Uchida $\mathrm{Y}$, Ueda $\mathrm{H}$ : Isoproterenol-induced non-uniform blood flow through ischemic and non-ischemic myocardium in the dog. Jap Ileart $\mathrm{J}$ 14: 32, 1973

19. Rosenblum I, Wohl A, Stein AA: Studies in cardiac necrosis. III. Metabolic effects of sympathomimetic amines producing cardiac lesions. Toxic Appl Pharmac 7: 344, 1965 